10 - ORIGINAL ARTICLE

EXPERIMENTAL ORTHOPAEDIC SURGERY

\title{
Osteoarthritis model induced by intra-articular monosodium iodoacetate in rats knee ${ }^{1}$
}

\author{
Sebastião Vieira de Morais ${ }^{I}$, Nicolau Gregori Czeczko", Osvaldo Malafaia' ${ }^{\mathrm{III}}$, Jurandir Marcondes Ribas Filho ${ }^{\mathrm{II}}$, João Batista \\ Santos Garcia $^{\mathrm{IV}}$, Marcelo Tizzot Miguel', Cassio Zini', Angeline Garcez Massignanv
}

DOI: http://dx.doi.org/10.1590/S0102-865020160110000010

'Fellow Master degree, Postgraduate Program in Principles of Surgery, Faculdade Evangélica do Paraná (FEPAR), Universidade Evangélica, Hospital de Curitiba, Medical Research Institute, Curitiba-PR, Brazil. Conception, design, intellectual and scientific content of the study.

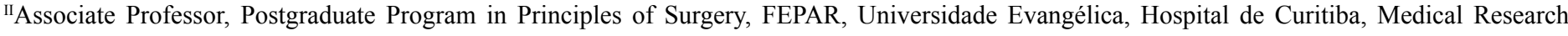
Institute, Curitiba-PR, Brazil. Scientific and intellectual content of the study, interpretation of data, critical revision.

IIIFull Professor, Postgraduate Program in Principles of Surgery FEPAR, Universidade Evangélica, Hospital de Curitiba, Medical Research Institute, Curitiba-PR, Brazil. Scientific and intellectual content of the study, interpretation of data, critical revision.

${ }^{\mathrm{IV}}$ Associate Professor, Universidade Federal do Maranhão (UFMA), Sao Luiz-MA, Brazil. Conception, design, intellectual and scientific content of the study.

${ }^{\mathrm{v}}$ Graduate student, FEPAR, Universidade Evangélica, Hospital de Curitiba, Medical Research Institute, Curitiba-PR, Brazil. Acquisition of data.

\section{ABSTRACT}

PURPOSE: To evaluate the usefulness of a knee osteoarthritis model through functional, radiological and microscopic changes of the synovial membrane.

METHODS: Forty eight rats were divided randomly into two groups. The first received $0.9 \%$ saline in the joint and corresponded to the control group. The second was submitted to experimental osteoarthritis of the right knee induced by monosodium iodoacetate and corresponded to the osteoarthritis group. All animals were subjected to comparative tests of forced ambulation and joint movements, inability to articulate and tactile allodynia on day 1 post-experiment by forced ambulation (Roto-rod test), joint assessment of disability (weight bearing test) and assessment of tactile allodynia (Von Frey test). After inflammatory induction they were divided into four subgroups corresponding to the scheduled death in 7, 14, 21 and 28 days when they were submitted to radiographic examination of the knee; arthrotomy and collection of the synovial membrane.

RESULTS: The osteoarthritis group showed significant differences compared to control group on days 7 and 14 in Roto-rod, in weight bearing and Von Frey tests in all days, and in radiological evaluation. Microscopic examination of the synovial membrane showed abnormalities of inflammatory character at all stages.

CONCLUSION: The osteoarthritis induced by intra-articular monosodium iodoacetate in rats knee is a good model to be used in related research, because it provides mensurable changes on joint movements, tactile allodynia, progressive radiological degeneration and microscopic inflammation of the synovial membrane, that represent markers for osteoarthritis evaluation

Key words: Osteoarthritis, Knee . Models, Animal. Rats. 


\section{Introduction}

Osteoarthritis is the most common chronic disease in elderly individuals ${ }^{1,2}$. It is defined by the American College of Rheumatology as a set of heterogeneous changes that induce painful joint symptoms and signs associated with defects in the integrity of articular cartilage and synovial membrane, in association with changes on articular bone margin ${ }^{3,4}$. The cartilage - the main target of the degenerative osteoarthritis changes - has two functions: to permit joint motion with minimal friction and to absorb shock preventing bone damage ${ }^{5-7}$. At the moment, many palliative drugs as anti-inflammatory, corticosteroids and opioids have been used in the treatment of the disease in humans; however, none of them stopped the evolutionary process of the lesion, which is the main goal of treatment ${ }^{8}$.

Ideal experimental model should reproduce the disease and allow joint study using biomechanical, radiological and microscopic evaluations of involved tissues. The pathogenesis should also be similar to tissue injury affecting the articulation of the human as well as the therapeutic response ${ }^{9}$. Chemical experimental models of osteoarthritis present fast installation results. Currently, the most used is with monosodium iodoacetate inhibitory activity of glyceraldehyde-3-phosphate dehydrogenase glycolysis and induces death of chondrocytes. Intra-articular injection leads to the destruction of chondrocytes in rodents and non-rodents. When it is used in rodent, cartilage lesions with loss of proteoglycan matrix and functional changes with stiffness similar to those observed in human osteoarthritis, are produced ${ }^{10,11}$. Given the importance of the synovial membrane and subchondral bone in the pathogenesis of joint pain in osteoarthritis, many experimental studies have been published with monosodium iodoacetate, but most of them only evaluated histopathological and radiological aspects, and not functional ones.

The present study aims to investigate the pain in static and dynamic joint inability, the tactile allodynia, and the correlation of radiological and histopathological changes.

\section{Methods}

This study was approved by the Ethics Committee in Research of the Universidade Federal do Maranhão (UFMA) $\left(\mathrm{n}^{\circ}\right.$. 17315/2011-65) and the procedures were performed in accordance to standards of the Brazilian College of Animal Experimentation $^{12,13}$.

The sample consisted of 48 male Wistar rats (Rattus norvegicus) adult male, weighing between 230-280 g. After the adaptation period they were randomly distributed into two groups of 24: control group (CG) and osteoarthritis group (OG). After a week, they underwent daily training in clinical measurement devices to adapt to them, facilitating motor and sensory capacity assessment after injury.

\section{Handling and joint induction of osteoarthritis}

The procedure in $\mathrm{CG}$ was intra-articular injection of saline solution $0.9 \%$ and in OG intra-articular injection of monosodium iodoacetate. Each group was subdivided into four subgroups. The CG animals were called CG-7, CG-14, CG-21 and CG-28 and the osteoarthritis group OG-7, OG-14, OG-21 and OG-28. This subdivision was made according to the day of the clinical evaluation and euthanasia. Behavioral assessment was performed on the first day before the induction of osteoarthritis and on the $7^{\text {th }}, 14^{\text {th }}, 21^{\text {st }}$, and $28^{\text {th }}$ days. Radiographs of the hind limbs and synovial membrane specimens withdrawn were realized in the same periods after euthanasia. The rats were anesthetized with thiopental $40 \mathrm{mg} / \mathrm{kg}$ intraperitoneally. The intra-articular puncture was performed with the right knee flexed at $90^{\circ}$ through the patellar ligament with $26 \mathrm{G}$ needle into the space between the tibia and femur. The injection site was localized through the palpation of tibial tuberosity; just above it there is a small depression representing the injection site. The needle insertion was performed by touching the intercondylar region of the femur. At this moment, with slight retraction, the substance is injected. In animals of CG was used $50 \mathrm{ml}$ of saline $0.9 \%$ in the right and left knees. In OG was introduced in right knee $2 \mathrm{mg}$ of monosodium iodoacetate in maximum volume of $50 \mathrm{ml}$ of $0.9 \%$ saline, and in left equal volume of saline $0.9 \%$ for itself control to be compared with $\mathrm{CG}$ results.

\section{Evaluation of forced ambulation (Roto-rod test)}

The animals were placed randomly on a rotating cylinder (Roto-rod, Figure 1) with increasing speed, forcing them to walk continuously to avoid falling. The performance index provided motor learning and use of the affected limb $b^{14,15}$. They were kept on the rotating bar for $5 \mathrm{~min}$ to become accustomed to the appliance. Five minutes after the adaptation period, they were again placed on Roto-rod and the rotational speed was increased from 5 to $35 \mathrm{rpm}$ in range of $5 \mathrm{~min}$. The latency to fall was measured automatically by a mechanical sensor at the base of the device. The first results of the assessment of motor activity of the animals occurred on day 1 in all animals, and then sequentially on days 7, 14, 21 and 28 
after induction. The forced ambulation was graduated. Was used a numerical scale ranging 5 to 1 , where 5 meant normal use of the limb; 4 slight claudication; 3 severe claudication; 2 intermittent disuse of the affected paw and 1 complete disuse of the affected paw $^{16}$.

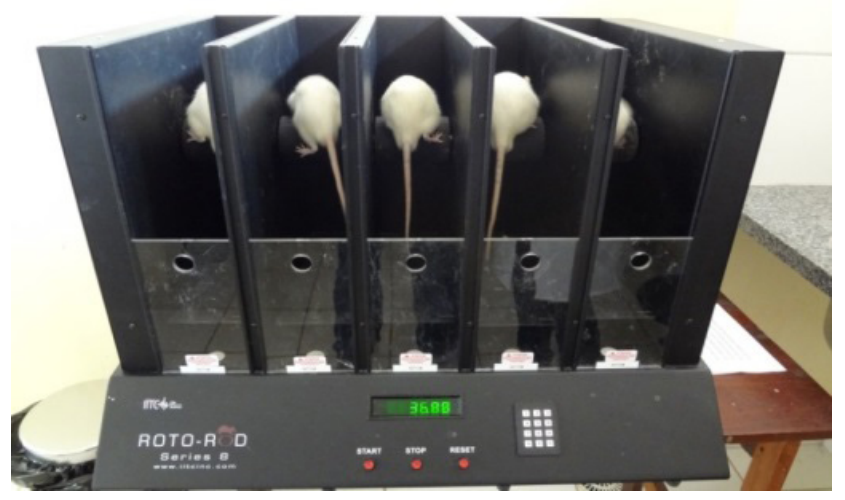

FIGURE 1 - Animals in forced ambulation in Roto-rod (model IITC Life Science, CA, USA).

\section{Joint assessment of disability (weight bearing test)}

Changes in weight distribution between the right hind limb (osteoarthritis) and left (without osteoarthritis) in all animals was used as an indicator of joint discomfort caused by handling of the joint. The capacitance test apparatus is shown in Figure 2 (model IITC Life Science, CA, USA) ${ }^{1,16}$.
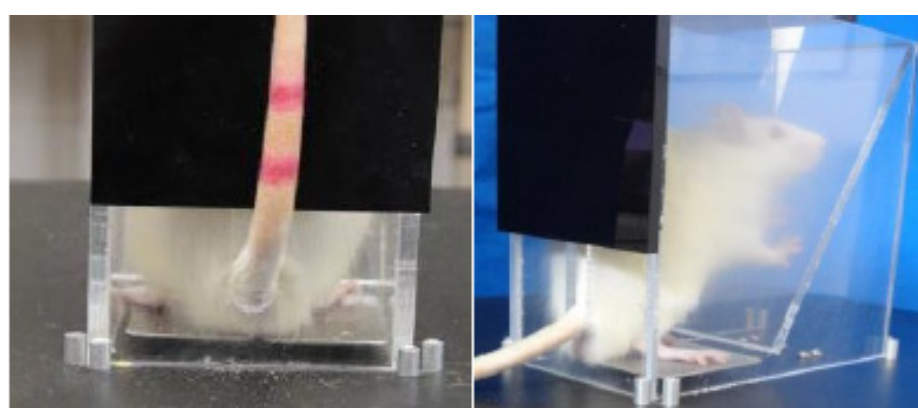

FIGURE 2 - Distribution of weight bearing on separate platforms.

Before measurements were taken, waited up period of 5 min was necessary for rat's adaptation to the device and the restart was only done when they had were in correct position, ie both hind limbs on the platforms and the fore limbs on plexiglass ramp. During testing, were observed and recorded the changes in weight distribution between right and left (contralateral control) to assess discomfort index in the right hind limb ${ }^{13}$. The weight exerted on each hind limb (measured in grams) was evaluated over a period of $5 \mathrm{~s}$. The final measurement of the weight distribution was given by the average of three measurements. Changes in the distribution were calculated as follows ${ }^{16,17}$.

Weight distribution $(\%)=\frac{\text { Weight on right side }}{\text { Weight on right side }+ \text { weight on the contralateral side }} \times 100$

\section{Assessment of tactile allodynia (Von Frey test)}

Was evaluated by digital analgesymeter (EFF Insight model 302, Sao Paulo, Brazil) calibrated to record maximum force of $150 \mathrm{~g}$, maintaining accuracy of $0.1 \mathrm{~g}$ to $80 \mathrm{~g}$ force. The contact pressure transducer with hind limb was performed using a disposable tip made of polypropylene with $0.5 \mathrm{~mm}$ diameter adapted to $\mathrm{it}^{18}$. The animals were placed in individual acrylic

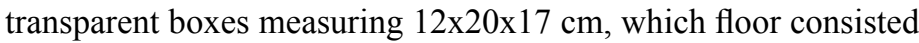
of a mesh network of $5 \mathrm{~mm}^{2}$ of non-malleable wire of $1 \mathrm{~mm}$ in thickness for $15 \mathrm{~min}$ before the experiment in order to adapt to the environment. Mirrors $25 \mathrm{~cm}$ below the boxes of experimentation were positioned for easy viewing in the plantar region of the hind limbs. Through the holes of the mesh the researcher applied linearly increasing pressure in the central region of the plantar hind limb until response was jolt ("flinch") stimulation of the pelvic limb (Figure 3). The stimuli were repeated up to six times in the ipsilateral and contralateral hind limbs until the animal presents three similar measures with clear "flinch" response after removal of the pelvic limb ${ }^{13}$.
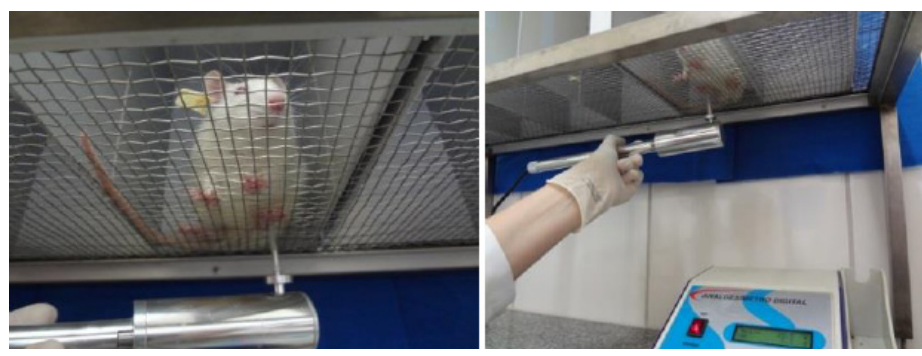

FIGURE 3 - Tip of the Von Frey device stimulating the limb between the mesh holes.

The nociceptive threshold was defined as the percentage of active suspension force to cause the affected ipsilateral hind limb and determined as follows ${ }^{16}$.

$$
\text { Nociceptive threshold }(\%)=\frac{\text { nociceptive threshold on the right side }}{\text { nociceptive threshold on right side }+ \text { nociceptive threshold of the contralateral side }} \times 100
$$




\section{Radiographic evaluation}

Procedure was performed immediately after euthanasia, before rigor mortis. Were used dental radiography periapical film unit. Radiographs were made in dorsoplantar position at full extension after euthanasia with usual development process. The images were analyzed by a radiologist without knowledge of joint and subgroup of animals evaluated. Were studied the changes of joint space, subchondral sclerosis and osteophyte formation. For radiological rating osteoarthritis scale was used ${ }^{19}$ ranging from 0 to 4 , where $0=$ no signs of osteoarthritis; $1=$ minimal osteophytes of doubtful meaning; 2 = definite osteophytes and joint space preserved; 3 = moderate osteophytes and narrowing joint space; 4 = significant joint space narrowing and subchondral sclerosis.

\section{Collection of synovial membrane and histopathology}

After euthanasia and radiographic evaluation, the animals were placed in dorsal recumbency. With Adssen forceps, skin and subcutaneous were freed from patellar tendon and the anterior aspect of the joint was exposed. Patellar tendon and patella were raised proximally from the lower portion of its insertion on the tibial tuberosity. With a scalpel, arthrotomy was made that allowed the identification of the synovial membrane following en-bloc resection.

After removal of the capsule the appearance of macroscopic lesions at the articular cartilage were evaluated (Figure 4).

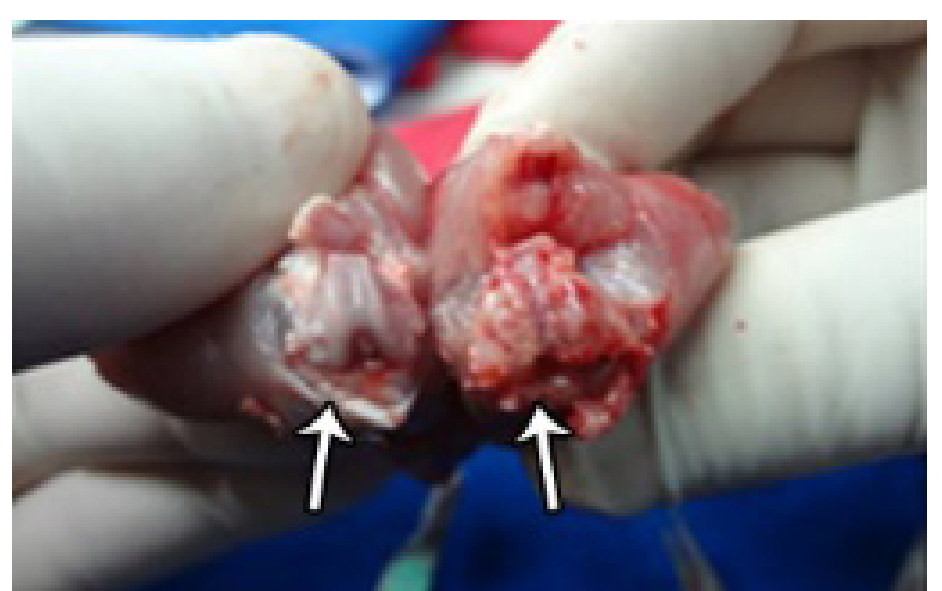

FIGURE 4 - Shows the comparison between two knees after capsule resection where $\mathrm{CG}$ can be seen on left side with chondral lesion although with normal aspect and on right side, OG with osteoarthritis.
After removal, the synovial membranes were prepared and stained with hematoxylin-eosin in the usual method. The inflammation was characterized as expansion of the synovial membrane by edema, fluid and fibrin with infiltration of macrophages, neutrophils, lymphocytes and plasma cells. To assess the degree of synovial inflammation the following grading system was used: grade 0 no inflammation; grade 1 minimal inflammation; grade 2 mild inflammation; grade 3 moderate inflammation; and grade 4 severe inflammation ${ }^{20}$. All samples were evaluated by the same pathologist, without knowledge of the animal and knee, to avoid different interpretation, as soon as it was based in qualitative analysis.

\section{Statistical analysis}

The comparison of the different experimental groups was performed using the Mann-Whitney test for ordinal qualitative variables and Student $t$ test for numerical variables. $p$ value $<0.05$ was indicated significance and the data were analyzed using the software Stat ${ }^{\circledR}$ GraphpadIn.

\section{Results}

\section{Forced ambulation evaluation (Roto-rod test)}

All CG rats showed similar evaluation on days 1, 7, 14, 21 and 28, and forced ambulation measured almost in all by the highest degree, 5 (Table 1). After injection of monosodium iodoacetate, the animals of OG showed significant reduction on gait score compared to the $\mathrm{CG}$, with a difference of 1 point in the score maintained in the subsequent analyzes of the $7^{\text {th }}$ to $14^{\text {th }}$ days of the experiment. From the $21^{\text {st }}$ to the $28^{\text {th }}$, the animals in both groups showed clinically similar march. In the comparison between CG and OG on day 1 there was no change. Statistically significant difference occurred in $7^{\text {th }}(p=0.0018)$ and $14^{\text {th }}(p=0.0067)$ days. In $21^{\text {st }}(\mathrm{p}=0.174)$ and $28^{\text {th }}(0.275)$, there was no difference between groups. The CG was 4.97 and the average OG was 4.53, as shown in Table 1 returning to normal standard. 
TABLE 1 - Evaluation of forced ambulation by Roto-rod test.

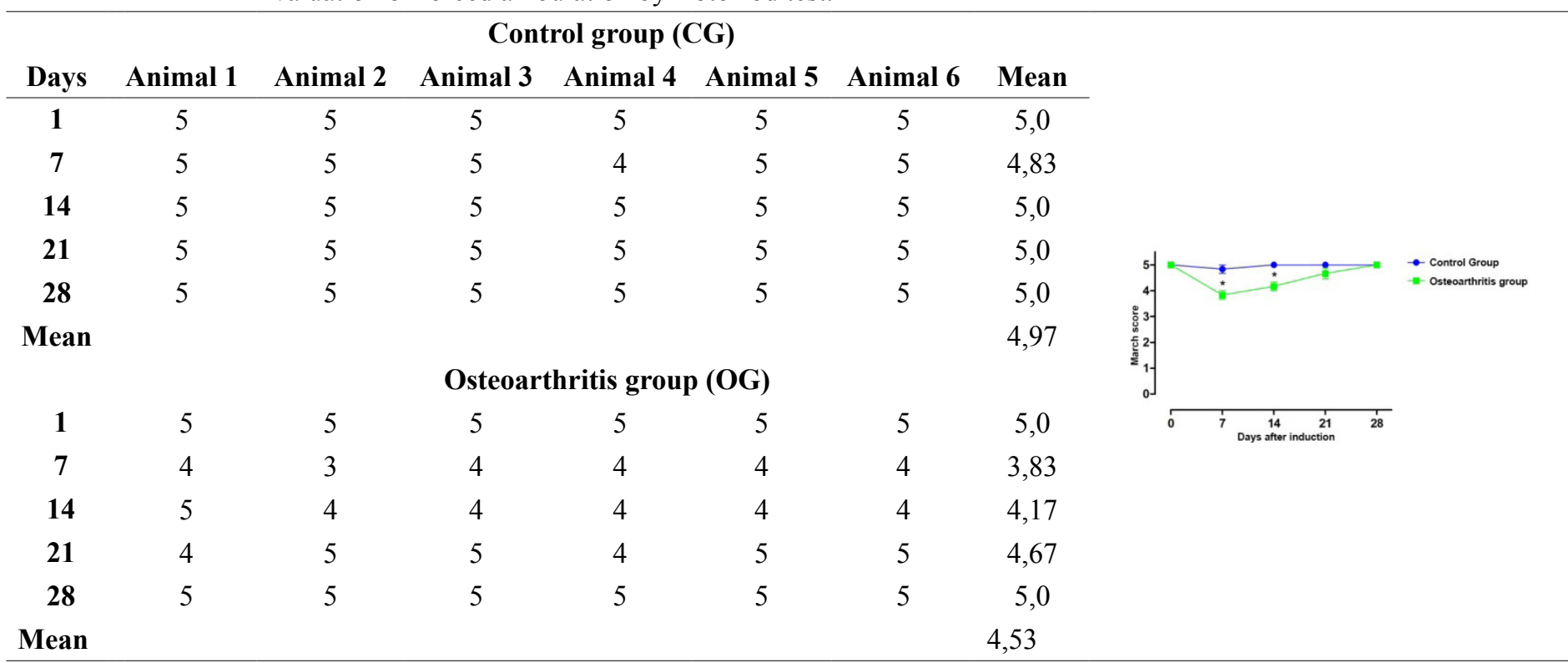

\section{Joint assessment of disability (weight bearing test)}

CG had symmetrical support in both hind limbs from beginning to end of the experiment with the final score of 50.96 showing absence of joint discomfort. After injection of monosodium iodoacetate, OG started showing signs of joint discomfort, distributing the weight predominantly on healthy pelvic limb (left side). In general, the alterations in the distribution of weight on the hind limbs followed biphasic distribution. In the first phase there was a marked reduction in the weight placed on the limb affected, having its maximum effect on the $7^{\text {th }}$ day postinduction $(\mathrm{p}=0.0001)$. By the $14^{\text {th }}$ day the OG animals had $40 \%$ distribution of weight on the affected leg. In the second phase, which started from the $21^{\text {th }}$ day, the asymmetry in the distribution of weight returned to accentuate with values ranging from $33-35 \%$ and was not resolved until the end of the experiment with the final score of 37.45. In the comparison between groups, on day 1 it was unchanged; it was different on day $7(\mathrm{p}<0.0001), 14(\mathrm{p}=0.0165)$, $21(\mathrm{p}<0.0001)$ and $28(\mathrm{p}=0.0001)$, being more significant on the $7^{\text {th }}$ day of the experiment (Table 2).

TABLE 2 - Inability to articulate the pelvic limbs in CG/OG animals by the weight bearing test.

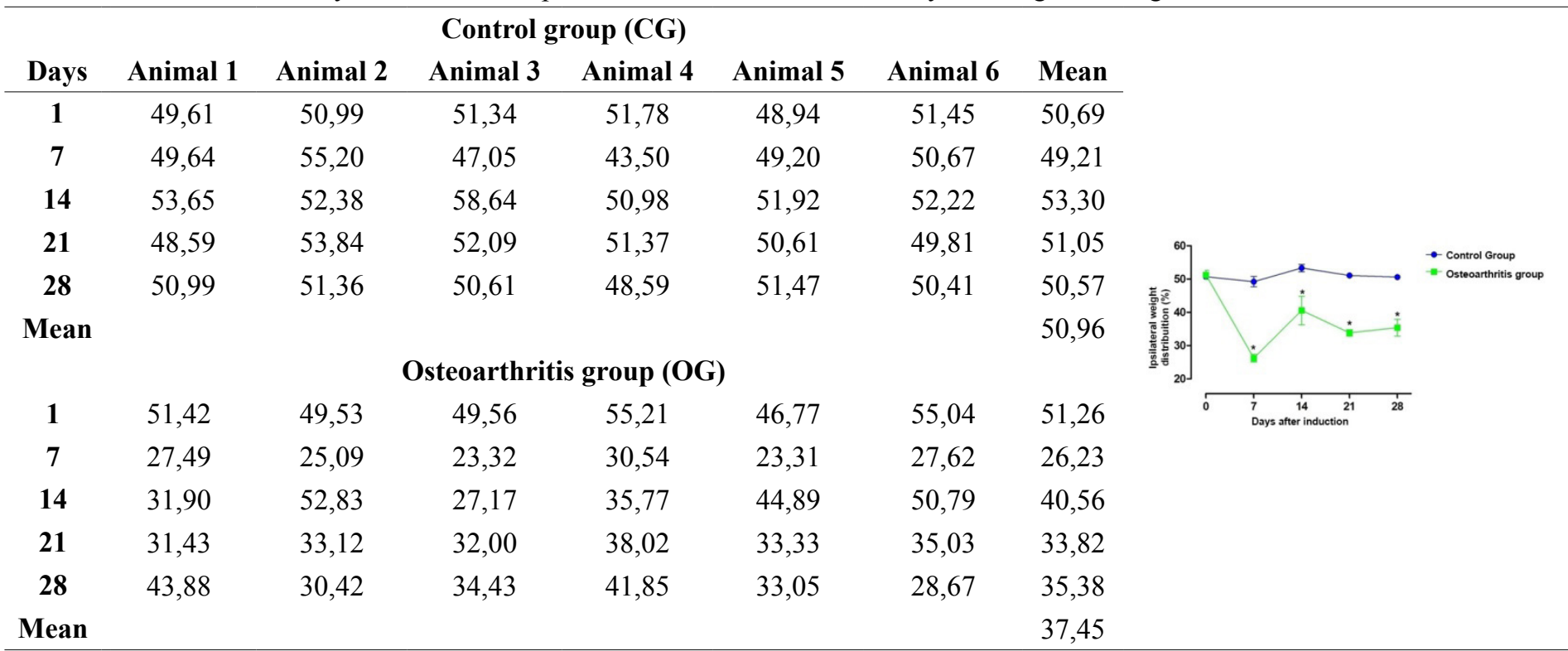

Assessment of tactile allodynia (Von Frey test)

When stimulated by the tip of Von Frey, CG animals showed similar responses from the first to the last test, demonstrating the absence of tactile allodynia with a final average of 49.80. The injection of monosodium iodoacetate induced tactile 
allodynia in animals, as demonstrated by the nociceptive paw withdrawal threshold of OG animals, on all days of the study; the final average was 37.66. The biggest change was observed on the $7^{\text {th }}$ day of the experiment $(\mathrm{p}<0.0001)$. From the $14^{\text {th }}$ day, the nociceptive withdrawal threshold of the OG paw increased again, but remained below the CG until the end of the experiment. In the comparison between groups, on day 1 was unchanged; difference was observed in $7^{\text {th }}(\mathrm{p}<0.0001), 14^{\text {th }}(\mathrm{p}=0.0046), 21^{\text {st }}(\mathrm{p}<0.0001)$ and $28^{\text {th }}(\mathrm{p}=0.0001)$ days (Table 3$)$.

TABLE 3 - Results of CG and OG when stimulated by Von Frey test.

\begin{tabular}{|c|c|c|c|c|c|c|c|c|c|}
\hline \multicolumn{10}{|c|}{ Control group (CG) } \\
\hline Days & Animal 1 & Animal 2 & Animal 3 & Animal 4 & Animal 5 & Animal 6 & Mean & & \\
\hline 1 & 50,00 & 48,84 & 46,42 & 50,90 & 50,00 & 49,57 & 49,29 & & \\
\hline 14 & 44,27 & 49,39 & 50,42 & 50,00 & 50,72 & 50,42 & 49,20 & & \\
\hline 21 & 49,86 & 51,14 & 49,70 & 49,15 & 50,00 & 50,00 & 49,98 & & - Control Group \\
\hline \multicolumn{9}{|c|}{ Osteoarthritis group (OG) } & \\
\hline 1 & 50,16 & 48,99 & 50,72 & 50,70 & 50,00 & 49,57 & 50,02 & 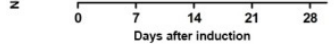 & \\
\hline 7 & 28,26 & 25,93 & 20,70 & 34,21 & 27,71 & 16,50 & 25,55 & & \\
\hline 4 & 39,59 & 33,33 & 42,25 & 36,95 & 37,19 & 50,00 & 39,89 & & \\
\hline
\end{tabular}

\section{Radiographic evaluation}

CG animals showed no radiographic changes in the first week of the experiment, but in the last had some slight modifications with final average of 0.5 , without significance. In the first week the OG animals showed no signs of joint damage; already on the $14^{\text {th }}$ day were no significant changes remaining until the end of the experiment, obtaining final average of 2.75. In the group comparison, there was no difference on day 7 and yes, significant, at $14(\mathrm{p}=0.0063), 21(\mathrm{p}=0.0049)$ and $28(\mathrm{p}=0.0063)$ days (Table 4, Figure 5).

TABLE 4 - Results of radiographic evaluation in CG and OG.

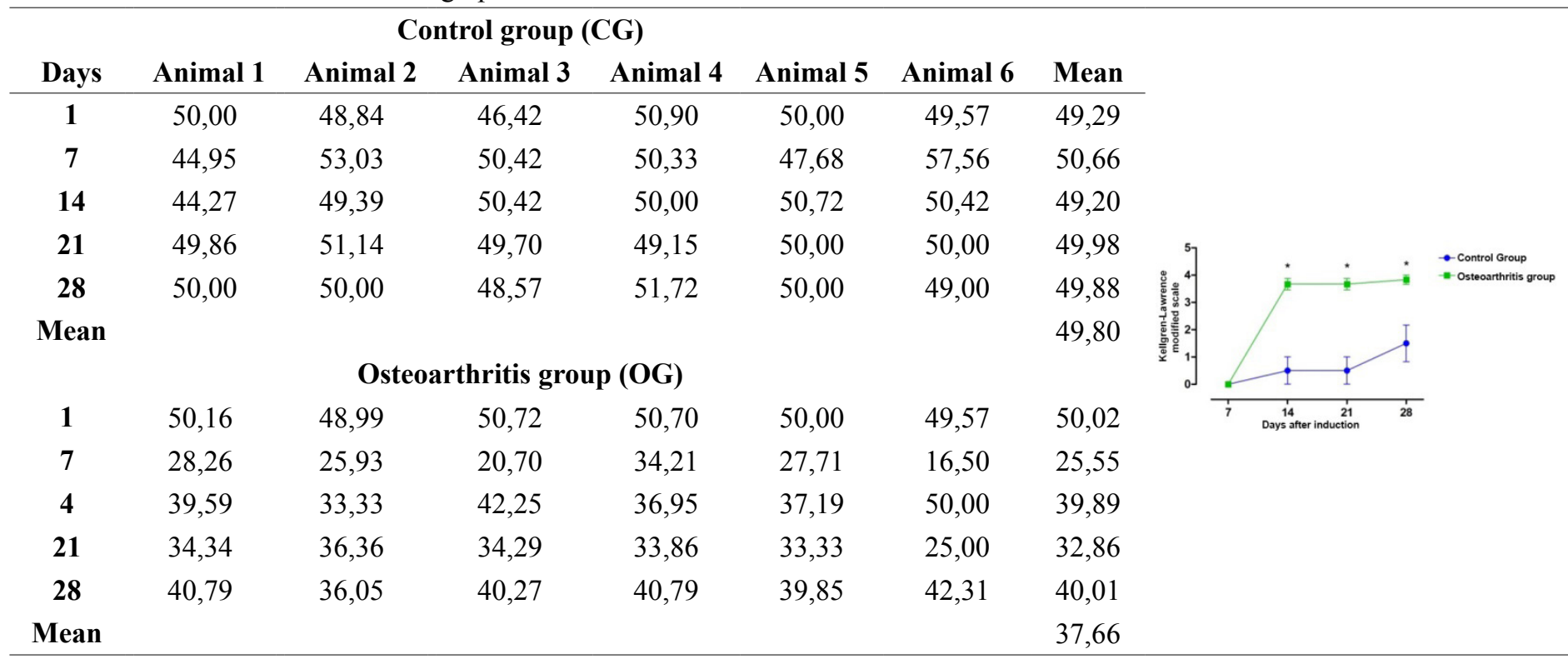



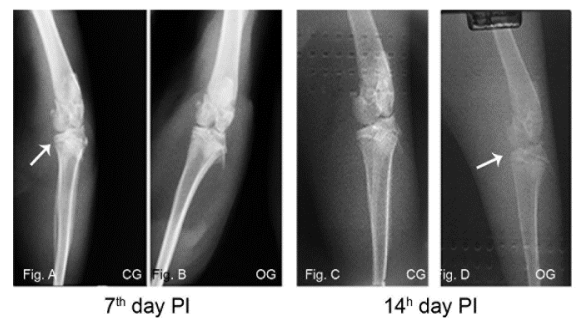

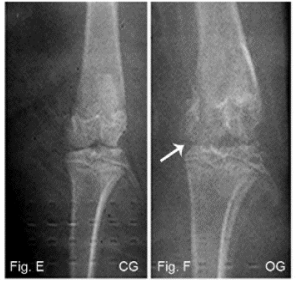

$21^{\text {st }}$ day PI

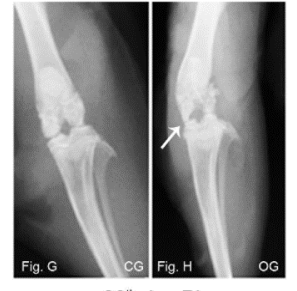

$28^{\text {th }}$ day PI

FIGURE 5 - Radiographic aspects: $7^{\text {th }}$ day (A. CG normal and B. GO normal); $14^{\text {th }}$ day (C. CG normal and D. GO with osteoarthritis - arrow); $21^{\text {st }}$ day (E. CG normal and E. GO with osteoarthritis - arrow); $28^{\text {th }}$ day (G. CG early osteoarthritis and $\mathbf{H}$. GO serious injury with destruction of femoral condyles - arrow).

\section{Microscopic analysis}

The synovial membrane by microscopy in CG and in the OG left knee served as self control, showed no changes in any animal from beginning to end of the study, final mean zero. The injection of monosodium iodoacetate induced histopathological changes in the synovial membrane on OG from the first to the last week, it was more evident on day 14, final average of 1.3. Comparing groups, there was significant differences in 7 $(\mathrm{p}=0.0049), 14(\mathrm{p}=0.0025), 21(\mathrm{p}=0.0025)$ and $28(\mathrm{p}=0.0035)$ days (Table 5)

TABLE 5 - Microscopic analysis of synovial membranes in CG and OG.

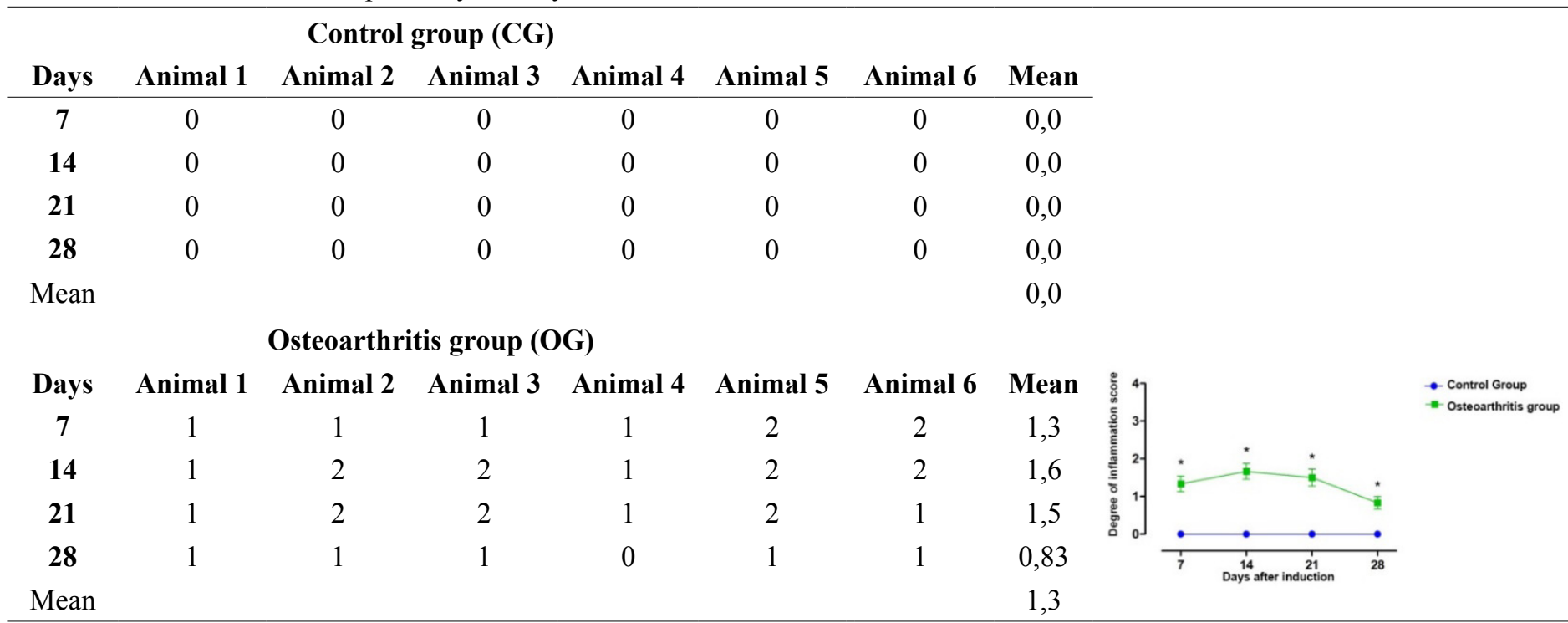

\section{Discussion}

In the experimental field, pain study in osteoarthritis using animals as models has generated great frustration. Large gains in science knowledge were obtained from animal experiments, but have not led to the development of new effective clinical medication, although the pain in experimental trials are similar to clinical pain. The complexity of the painful phenomenon is still difficult to assess, because various factors such as gender, genotype and media can interfere. Therefore, new models of pain should be pursued $^{21}$. Induced monosodium iodoacetate osteoarthritis shows death and degeneration of chondrocytes, which are responsible for maintaining the integrity of the articular cartilage ${ }^{22}$. In association with chondral injury, reparative inflammation occurs leading to bone sclerosis, pain decrease in joint space, similar to human osteoarthritis $^{23}$. In addition to inflammation, it can be observed constant bone degeneration and osteophyte formation, seen in the radiographic images shown in this experiment. This model has served as the basis for experimental treatment of osteoarthritis in various ways $^{24-26}$.

The Roto-rod, although initially designed for forced ambulation on gait in lesions of the cerebellum ${ }^{15}$, is also used in the grading of joint function in experimental neurological compressions $^{27}$, and joint changes in experimental arthritis of the knees ${ }^{16,25}$. This study showed that the greatest difference occurred in 7 and 14 days after induction. Interestingly, after the inflammatory phase of the early days the animals develop motor learning to walk trying to disguise having pain during walking, 
so that they are not target for predators ${ }^{28}$. When subjected to the measurement of articular disability - weight bearing - was observed that all OG animals especially in the first inflammatory phase of the disease had prevalence of less support on the right side, where osteoarthritis was induced. Authors ${ }^{1,17,29}$ tested monosodium iodoacetate in various dosages, ranging from $0.1 \mathrm{mg}$ to $3 \mathrm{mg}$, and concluded that higher dosage leads to higher sensitivity to detect the weight bearing joint failure, particularly in the acute phase. Tactile allodynia is defined as painful response to a stimulus that normally is painless ${ }^{13}$ and occurs in patients with osteoarthritis ${ }^{30}$. The present study found biphasic response results more significant in the first phase and inflammatory-like weight bearing. The appearance of radiological signs of osteoarthritis in various animal species can be precocious ${ }^{30}$. This study in chronic phase showed signs of joint degeneration, narrowing joint space, bone sclerosis, osteophytes in all animals; final assessments identified significant atrophy of the femoral condyles with extensive bone loss. This study supported this hypothesis, both in bone degeneration and in histological changes in cartilage analysis. Comparing the changes of monosodium iodoacetate in rat's cartilage with human cartilage, similar histological changes were found in literature review, and so this model is an important instrument to study new substances that can be used in mankind.

\section{Conclusion}

The osteoarthritis induced by intra-articular monosodium iodoacetate in rats knee is a good model to be used in related research, because it provides mensurable changes on joint movements, tactile allodynia, progressive radiological degeneration and microscopic inflammation of the synovial membrane, that represent markers for osteoarthritis evaluation

\section{References}

1. Bove SE, Calcaterra SL, Brooker RM, Huber CM, Guzman RE, Juneau PL, Schrier DJ, Kilgore KS. Weight bearing as a measure of disease progression and efficacy of anti-inflammatory compounds in a model of monosodium iodoacetate-induced osteoarthritis. Osteoarthritis Cartilage. 2003 Nov;11(11):821-30. PMID: 14609535.

2. Harvey VL, Dickenson AH. Behavioural and electrophysiological characterisation of experimentally induced osteoarthritis and neuropathy in C57Bl/6 mice. Mol Pain. 2009 Apr 20;5:18. doi: 10.1186/1744-8069-5-18.

3. Asada S, Akagi M, Matsushita T, Hashimoto K, Mori S, Hamanishi C. Effects of cartilage remnants of the posterior femoral condyles on femoral component rotation in varus knee osteoarthritis. Knee. 2012 Jun;19(3):185-9. doi: 10.1016/j.knee.2011.02.008.

4. Coimbra IB, Pastor EH, Greve JMD, Puccinelli MLC, Fuller R, Cavalcanti FS, Maciel FMB, Honda E. Consenso brasileiro para tratamento da osteoartrite (artrose). Rev Bras Reumatol. 2002;42(6):371-4.

5. Hunter DJ, Felson DT. Osteoarthritis. BMJ. 2006 Mar 18;332(7542):639-42. PMID: 16543327.

6. Gleghorn JP, Jones AR, Flannery CR, Bonassar LJ. Boundary mode lubrication of articular cartilage by recombinant human lubricin. J Orthop Res. 2009 Jun;27(6):771-7. doi: 10.1002/jor.20798.

7. Waller KA, Zhang LX, Elsaid KA, Fleming BC, Warman ML, Jay GD. Role of lubricin and boundary lubrication in the prevention of chondrocyte apoptosis. Proc Natl Acad Sci U S A. 2013 Apr 9;110(15):5852-7. doi: 10.1073/pnas.1219289110.

8. Cialdai C, Giuliani S, Valenti C, Tramontana M, Maggi CA. Effect of Intra-articular 4-(S)-amino-5-(4-\{4-[2,4-dichloro-3-(2,4dimethyl-8-quinolyloxymethyl)phenylsulfonamido]-tetrahydro-2H4-pyranylcarbonyl\} piperazino)-5-oxopentyl](trimethyl)ammonium chloride hydrochloride (MEN16132), a kinin B2 receptor antagonist, on nociceptive response in monosodium iodoacetateinduced experimental osteoarthritis in rats. J Pharmacol Exp Ther. 2009 Dec;331(3):1025-32. doi: 10.1124/jpet.109.159657.

9. LittleCB,SmithMM.Animalmodelsofosteoarthritis.CurrRheumatol Rev.2008;4(3):175-82. doi: 10.2174/157339708785133523

10. Schuelert N, McDougall JJ. Grading of monosodium iodoacetateinduced osteoarthritis reveals a concentration-dependent sensitization of nociceptors in the knee joint of the rat. Neurosci Lett. 2009 Nov 13;465(2):184-8. doi: 10.1016/j.neulet.2009.08.063.

11. Combe R, Bramwell S, Field MJ. The monosodium iodoacetate model of osteoarthritis: a model of chronic nociceptive pain in rats? Neurosci Lett. 2004 Nov 11;370(2-3):236-40. PMID: 15488329.

12. Pinheiro BB, Fiorelli AI, Gomes OM. Effects of ischemic postconditioning on left ventricular function of isolated rat hearts. Rev Bras Cir Cardiovasc. 2009 Jan-Mar;24(1):31-7. PMID: 19504016.

13. Fernihough J, Gentry C, Malcangio M, Fox A, Rediske J, Pellas T, Kidd B, Bevan S, Winter J. Pain related behaviour in two models of osteoarthritis in the rat knee. Pain related behaviour in two models of osteoarthritis in the rat knee. Pain. 2004 Nov;112(1-2):83-93. PMID: 15494188.

14. Shiotsuki H, Yoshimi K, Shimo Y, Funayama M, Takamatsu Y, Ikeda K, Takahashi R, Kitazawa S, Hattori N. A rotarod test for evaluation of motor skill learning. J Neurosci Methods. 2010 Jun 15;189(2):180-5. doi: 10.1016/j.jneumeth.2010.03.026.

15. Pinto WBVR, Ko GM. Teste de Roto-rod: contribuições no estudo das doenças neuromusculares, das síndromes extrapiramidais e das ataxias cerebelares. RESBCAL. 2012;1(2):202-12.

16. Kalff KM, El Mouedden M, van Egmond J, Veening J, Joosten L, Scheffer GJ, Meert T, Vissers K. Pre-treatment with capsaicin in a rat osteoarthritis model reduces the symptoms of pain and bone damage induced by monosodium iodoacetate. Eur J Pharmacol. 2010 Sep 1;641(2-3):108-13. doi: 10.1016/j.ejphar.2010.05.022.

17. Stevenson GW, Mercer H, Cormier J, Dunbar C, Benoit L, Adams C, Jezierski J, Luginbuhl A, Bilsky EJ. Monosodium iodoacetateinduced osteoarthritis produces pain-depressed wheel running in rats: implications for preclinical behavioral assessment of chronic pain. Pharmacol Biochem Behav. 2011 Mar;98(1):35-42. doi: 10.1016/j.pbb.2010.12.009.

18. Vivancos GG, Verri WA Jr, Cunha TM, Schivo IR, Parada CA, Cunha FQ, Ferreira SH. An electronic pressure-meter nociception paw test for rats. Braz J Med Biol Res. 2004 Mar;37(3):391-9. PMID: 15060709.

19. Kellgren JH, Lawrence JS. Radiological assessment of osteoarthrosis. Ann Rheum Dis. 1957 Dec;16(4):494-502. PMID: 13498604.

20. Gerwin N, Bendele AM, Glasson S, Carlson CS. The OARSI histopathology initiative - recommendations for histological 
assessments of osteoarthritis in the rat. Osteoarthritis Cartilage. 2010 Oct;18 Suppl 3:S24-34. doi: 10.1016/j.joca.2010.05.030.

21. Mogil JS. Animal models of pain: progress and challenges. Nat Rev Neurosci. 2009 Apr;10(4):283-94. doi: 10.1038/nrn2606.

22. Kobayashi K, Imaizumi R, Sumichika H, Tanaka H, Goda M, Fukunari A, Komatsu H. Sodium iodoacetate-induced experimental osteoarthritis and associated pain model in rats. J Vet Med Sci. 2003 Nov;65(11):1195-9. PMID: 14665748.

23. Janusz MJ, Hookfin EB, Heitmeyer SA, Woessner JF, Freemont AJ, Hoyland JA, Brown KK, Hsieh LC, Almstead NG, De B, Natchus MG, Pikul S, Taiwo YO. Moderation of iodoacetate-induced experimental osteoarthritis in rats by matrix metalloproteinase inhibitors. Osteoarthritis Cartilage. 2001 Nov;9(8):751-60. PMID: 11795995.

24. Cifuentes DJ, Rocha LG, Silva LA, Brito AC, Rueff-Barroso CR, Porto LC, Pinho RA. Decrease in oxidative stress and histological changes induced by physical exercise calibrated in rats with osteoarthritis induced by monosodium iodoacetate. Osteoarthritis Cartilage. 2010 Aug;18(8):1088-95. doi: 10.1016/j. joca.2010.04.004.

25. Albuquerque PC, Aguiar JL, Pontes Filho NT, Mello RJ, Olbertz CM, Albuquerque PE, Paz ST, Santos AH, Maia CS. A comparative study of the areas of osteochondral defects produced in femoral condyles of rabbits treated with sugar cane biopolymer gel. Acta Cir Bras. 2015 Nov;30(11):770-7. doi: 10.1590/S0102865020150110000008.

26. Mapp PI, Sagar DR, Ashraf S, Burston JJ, Suri S, Chapman V, Walsh DA. Differences in structural and pain phenotypes in the sodium monoiodoacetate and meniscal transection models of osteoarthritis. Osteoarthritis Cartilage. 2013 Sep;21(9):1336-45. doi: 10.1016/j. joca.2013.06.031.

27. GravaALS,Ferrari LF,Parada CA,Defino HLA. Modelo experimental para o estudo da hérnia do disco intervertebral. Rev Bras Ortop. 2008 Apr;43(4):116-25. doi: 10.1590/S0102-36162008000300003.
28. Roughan JV, Flecknell PA. Evaluation of a short duration behaviourbased post-operative pain scoring system in rats. Eur J Pain. 2003;7(5):397-406. PMID: 12935791.

29. Bajaj P, Bajaj P, Graven-Nielsen T, Arendt-Nielsen L. Osteoarthritis and its association with muscle hyperalgesia: an experimental controlled study. Pain. 2001 Aug;93(2):107-14.

30. Kamekura S, Hoshi K, Shimoaka T, Chung U, Chikuda H, Yamada T, Uchida M, Ogata N, Seichi A, Nakamura K, Kawaguchi H. Osteoarthritis development in novel experimental mouse models induced by knee joint instability. Osteoarthritis Cartilage. 2005 Jul;13(7):632-41. PMID: 15896985.

\section{Correspondence:}

Sebastião Vieira de Morais

Alameda Augusto Stellfeld, 1980

80730-150 Curitiba - PR Brasil

Tel.: (55 41)3240-5488

sebastianma@bol.com.br

Received: July 14, 2016

Review: Sep 15, 2016

Accepted: Oct 16, 2016

Conflict of interest: none

Financial source: none

${ }^{1}$ Research performed at Postgraduate Program in Principles of Surgery, Faculdade Evangélica do Paraná (FEPAR), University Evangelic Hospital of Curitiba, Medical Research Institute, Curitiba-PR, Brazil. Part of Master degree thesis, Postgraduate Program in Principles of Surgery. Tutor: Nicolau Gregori Czeczko. 